\title{
Recurrence risks and prognosis in severe sporadic osteogenesis imperfecta
}

\author{
E M THOMPSON*, I D YOUNG + , C M HALL \\ From ${ }^{*}$ the Mothercare Unit of Paediatric Genetics, Institute of Child Health, London; the \\ Department of Child Health, Leicester Royal Infirmary, Leicester; and $\ddagger$ the Department of Radiology, \\ The Hospital for Sick Children, Great Ormond Street, London.
}

SUMMARY A study was carried out in the United Kingdom of patients with severe osteogenesise imperfecta (OI), born with fractures to normal parents, in order to determine recurrence risks. A total of 105 cases from 98 families survived the perinatal period and 60 cases from 57 families were stillborn or died during the first week of life. The majority of the perinatal survivors $\Theta$ correspond to the overlapping group of Sillence type III and sporadic type IV OI. In 40 of these, 은 the radiograph at birth was available and in 37 it showed a characteristic appearance similar tothat described previously for type III OI. The other three cases had radiological type IIB OI at $\cong$ birth and died before 26 months of age. The patients with perinatally lethal OI were subdivided on radiological appearance into Sillence type IIA (30 cases, described in the previous paper), $\vec{\oplus}_{\infty}$ type IIB (12 cases from 11 families), and type IIC (three cases from three families), and in five. ${ }^{.}$ cases from three families the radiological appearance was the same as that of the 37 perinatalo survivors described above. Ten cases from 10 families were not classified because their radiographs were unavailable.

To analyse the empirical recurrence risks, patients were grouped according to radiological\% appearance at birth. Those with a type III-like pattern numbered 42 cases and they were grouped $\stackrel{\mathbb{Q}}{\Omega}$ with the other cases of severe deforming OI who survived the perinatal period, for whom no $x$ ray을 at birth was available, making a total of 107 cases. Taking one affected child per family as the 3 proband, there were 98 probands. They had 146 sibs, of whom 10 were affected, giving an empirical recurrence risk of $6 \cdot 9 \%$. This is consistent with the disease arising as a new dominant mutation in about three quarters of families and as a recessive in about one quarter in this heterogeneous group. It is reasonable to give a recurrence risk of up to $25 \%$ in cases witho parental consanguinity and a risk of $4.4 \%$ in cases with unrelated parents. Fifteen patients (14… probands) with Sillence type IIB OI had 13 sibs, one affected, giving an empirical recurrence risko of $7.7 \%$. The parents were consanguineous in three families and the evidence for autosomal recessive inheritance for the majority in this group is probably stronger. The three patients with윽 type IIC OI had three healthy sibs and the 10 unclassifiable perinatally lethal cases had 22 sibs, all normal.

The radiological appearance at birth predicts prognosis to some extent; essentially, the better the bone morphology and mineralisation, the longer the survival.

There is increasing evidence that osteogenesis imperfecta (OI) is a group of monogenic disorders involving the collagen genes. Where there is a family history, the type of inheritance and recurrence risk is usually self-evident. Single cases in a family are likely to represent either new dominant mutations with no recurrence risk or autosomal recessive inheritance with a $25 \%$ recurrence risk, but there is

Received for publication 22 December 1986

Revised version accepted for publication 13 February 1987. no reason to assume that any particular clinicalo subgroup has just one pattern of inheritance.

The division of OI into four main types by Sillence et $a l^{1}$ in 1979 highlighted the diversity of OI and? provided a useful classification which has been 0 widely used by clinicians. Types I and IV wereo autosomal dominantly inherited; sclerae were blue in type I and normal in type IV. Bone deformity was $\vec{Q}$ generally mild in type I but in type IV deformity waso variable and could be severe. Type II, the "perinat- 
ally lethal' form, was later subdivided into three radiological subgroups by Sillence $e \mathrm{al}^{2}$ in 1984 . The authors "suggest that most cases of OI type II represent autosomal recessive traits".

Patients with type III OI developed severe progressive deformity and had pale blue or normal sclerae. Although all 21 patients in the original paper were sporadic, the authors suggested that autosomal recessive inheritance was likely, based on consanguinity of parents in two families and on previous reports of affected sib pairs. While recognising that some cases may be due to autosomal dominant new mutation, type III OI was shown as autosomal recessive in their table $7,{ }^{1}$ and this has become widely quoted. ${ }^{3}{ }^{4}$ Subsequently, the authors saw five families with either multiple affected sibs or parental consanguinity. ${ }^{56}$ More recently, Sillence et $a l^{7}$ have described eight sibships in seven families with multiple affected sibs (seven sibships) or consanguineous parents (one sibship); two were being re-reported. Having originally classified type III OI on clinical grounds of severe progressively deforming OI, they now use the criterion of being recessive to redefine the range of severity in type III OI, so that "the OI type III phenotype does not necessarily equate with progressively deforming OI, and probably only a proportion of cases with severe deformity and normal sclerae have OI type III".

For purposes of genetic counselling, the Sillence classification has some limitations. Because of overlapping features between types, single cases can be difficult to classify. This is particularly true of single cases of types III and IV which cannot be distinguished with certainty. There is increasing evidence for genetic heterogeneity within types, particularly in type III OI. There are instances of probable autosomal recessive severe deforming OI, with reports of affected sibs ${ }^{7-14}$ and of single cases in a sibship or affected cousins with parental consanguinity. ${ }^{7}{ }^{15-17}$ It is noteworthy, however, that several studies record a paucity of affected sibs ${ }^{18-20}$ or note that the majority of severe OI are sporadic. ${ }^{21}$

Genetic counselling is difficult in severe 'sporadic' OI because single cases of type III and IV cannot be distinguished reliably and there are no clinical or radiological features which allow identification of an isolated case of recessive type III OI. To resolve this genetic counselling dilemma we determined recurrence risks and assessed prognosis in this severe 'sporadic' group of patients.

\section{Methods}

ASCERTAINMENT OF CASES

There is no single criterion which will include all patients with severe OI. Nevertheless, the majority of patients with severe OI will have fractures at birth, ${ }^{22}$ making this the best inclusion criterion for this group of patients. Ascertainment of cases of OI with fractures at birth requires different sources for patients who died perinatally (defined as stillborn babies or those who died within one week of birth) and for those who survived the perinatal period.

\section{(a) Patients who survived the perinatal period}

These were ascertained largely through the Brittle Bone Society (BBS), a support group in the United Kingdom for patients with $\mathrm{OI}$ and their families, founded in 1968. Patients known to the BBS include the majority of those with severe OI for two reasons. First, such patients and their families require much support in terms of physical aids and advice on management of daily activities. The BBS has a reputation for providing generously for these needs. Secondly, the BBS has developed an informal network of communication, so that new cases are rapidly brought to their attention and offered their services. On joining the BBS (which does not require payment), patients or their families complete a short questionnaire on certain clinical data, including whether or not fractures were present at birth. The ascertainment of these cases is summarised in table 1 . The initial sample of patients includes all patients known to the BBS to the end of July 1984, who had fractures at birth. These numbered 185 cases from 179 families. Two patients were excluded as no information about their pedigree was available. Fifty-two cases with proven autosomal dominant OI, that is, with an affected parent, were excluded. The remaining families were approached by the committee of the BBS. Families of 25 patients (all single cases) did not wish to participate and so had to be excluded as there was no other avenue of access to information about them. The 100 families of 106 cases who agreed to participate in the study were contacted by one of the authors (EMT). During the course of the study, to June 1985, a further 23 cases (from 22 families) came to light and were studied. These were referred by clinical geneticists who knew of our interest in OI and 10 of the cases were born during the time of the study. Thus, the group studied who were born with fractures, whose parents were unaffected, number 129 cases from 122 families (table 1).

\section{(b) Patients with perinatally lethal $\mathrm{OI}$}

Ascertainment of perinatally lethal cases was through clinical geneticists in the UK, as described by Young et al (see preceding paper). A total of 60 cases from 57 families was ascertained. Only two of these families were known to the BBS, which emphasises the need for separate ascertainment of perinatally lethal cases and cases surviving the perinatal period. 
TABLE 1 Ascertainment of perinatal survivors.

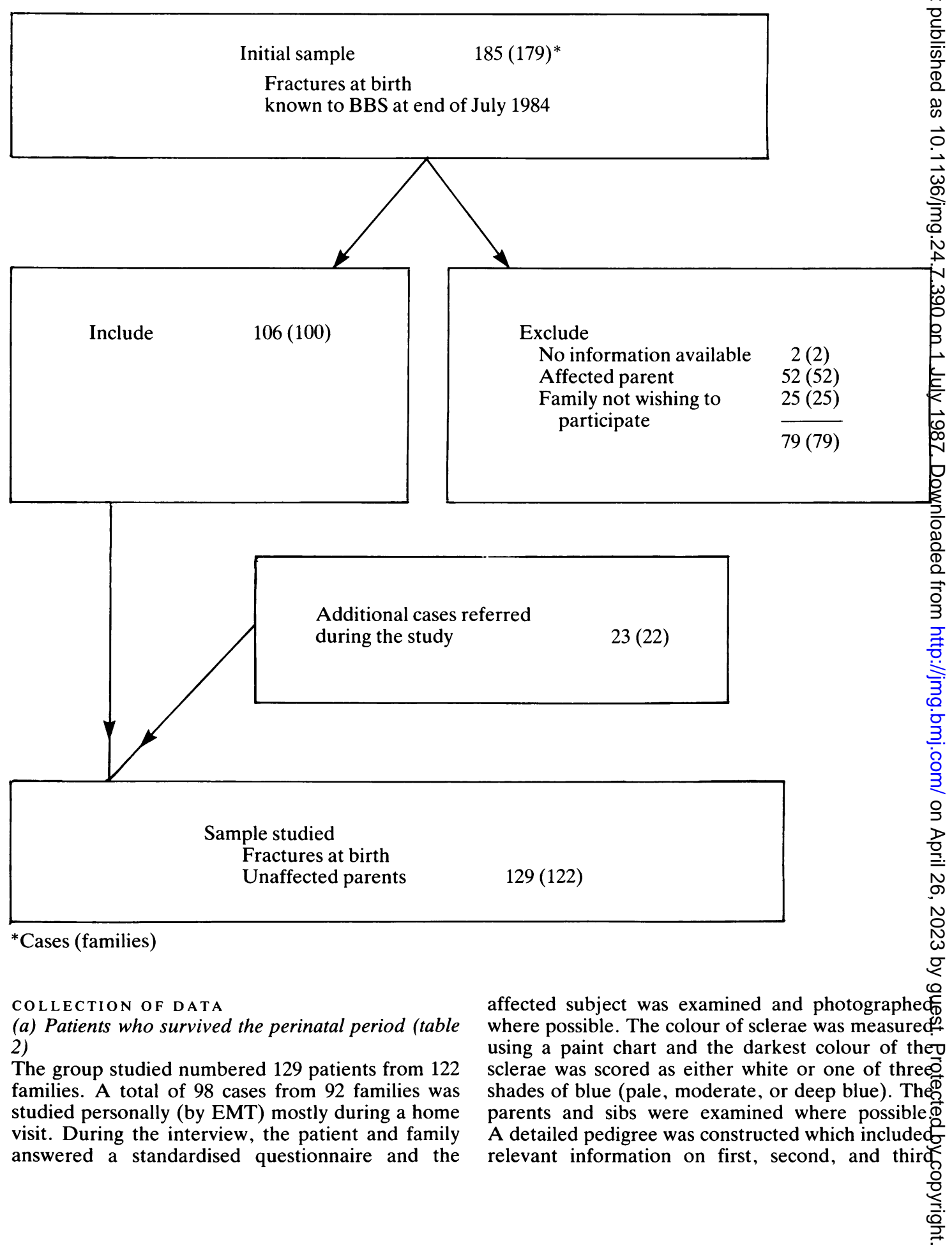


Recurrence risks and prognosis in severe sporadic osteogenesis imperfecta

TABLE 2 Collection of data on perinatal survivors, who had fractures at birth and normal parents, and exclusion of cases of probable type I new mutation, to arrive at sample analysed for recurrence risks.
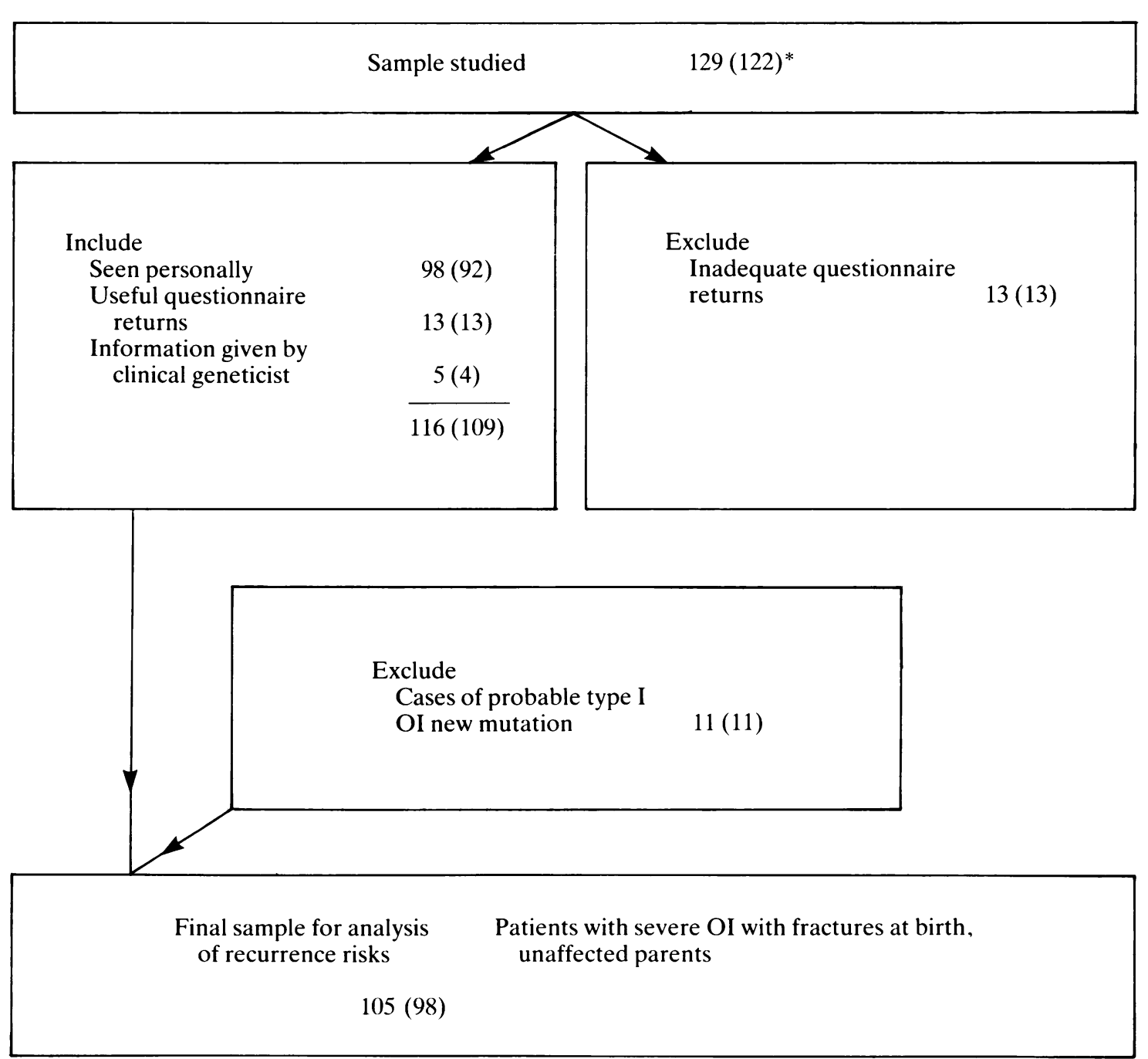

${ }^{*}$ Cases (families)

degree relatives where possible. Further information was obtained from hospital records where necessary. Twenty-six families who were relatively inaccessible were sent a postal questionnaire and 13 provided useful returns including a photograph of the affected subject. The 13 who either did not return the questionnaire or gave inadequate information are excluded. The information on five cases from four families was provided by a consultant clinical geneticist. In all cases, exhaustive attempts were made to obtain all the radiographs of each affected subject. Radiographs were available in 97 cases and in 40 cases radiographs taken in the first week of life were also available.

(b) Patients with perinatally lethal $\mathrm{OI}$

Collection of data was described in the preceding paper. 


\section{Results}

The purpose of this report is to present data relating to recurrences in sibships and to show radiographical appearances in the neonatal period which help in prediction of immediate prognosis. Further clinical analyses are in preparation.

A. CLASSIFICATION OF PATIENTS

1. Patients who survived the perinatal period (first week of life)

Information on 116 cases from 109 families was obtained.

\section{(a) Exclusion of probable cases of type I OI new mutations}

It is well known that patients with the milder type I OI may present with fractures at birth. ${ }^{1}$ Eleven such cases could be identified on the basis that they had little or no bony deformity associated with mild radiological changes, minimal handicap (they were all able to walk well unaided), and moderately or deep blue sclerae. Their heights were below average, but were all greater than $-6.0 \mathrm{SD}$ below the mean, with an average SD of $-4 \cdot 0$ (range $-2 \cdot 8$ to $-6.0 \mathrm{SD})$. All but one of these were seen personally. In nine cases the mother reported that at birth the number of fractures present was one (two cases), two (four cases), three (one case), four (one case), 14 (one case). In two cases the number of fractures at birth was unknown. Neonatal radiographs of two of these patients were available; they confirmed the presence of two and four fractures, respectively, and showed good length and modelling of long bones, and mild bowing only of the femora and tibiae in one (fig 1). These 11 cases with probable type I OI are excluded from the analysis of recurrence risks, on the basis that they represent known new dominant mutations of type I OI and their inclusion would falsely lower the recurrence risks. This left 105 cases from 98 families with severe OI, who were born with fractures to normal parents and who survived the first week of life (table 2).

(b) Ages of patients and severity of $\mathrm{OI}$

The ages of the 105 cases ranged from 16 days to 54 years, with a mean of about 12 years. Four-fifths were under 20 years. Twenty-six of the 105 had died $(25 \%)$, all before 20 years. Of these, $18(69 \%)$ had died before 26 months and $24(92 \%)$ by 10 years. There was progressive bone deformity and handicap was generally severe: of the 70 cases over five years of age, $70 \%$ had never been able to walk and only three could walk well unaided. Sclerae were white in six, pale blue in 46 , moderately blue in 13 , deep blue in 26 , and unknown in 14 . The heights measured in

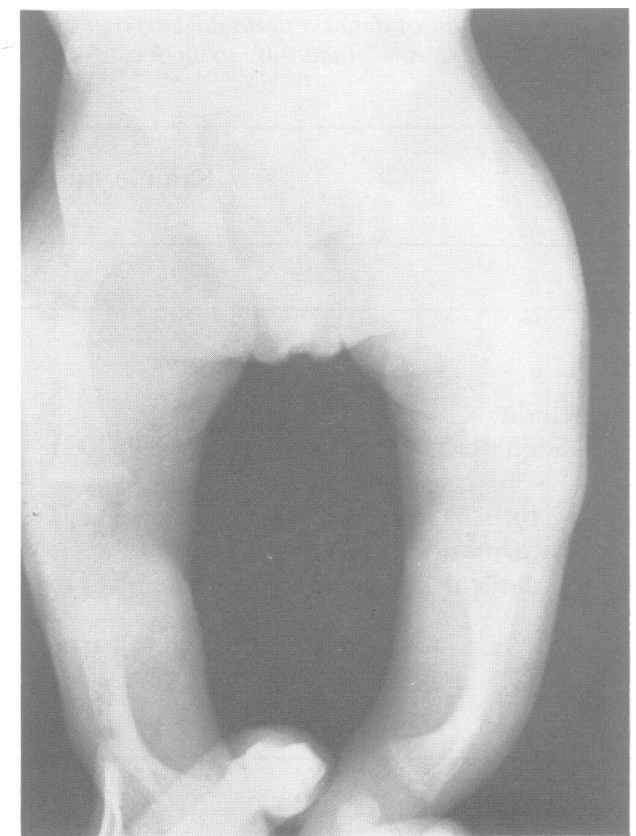

FIG 1 Radiograph taken on day 1 of a case of probable type I OI who represents a new mutation. Note good length and modelling of long bones and only mild bowing.

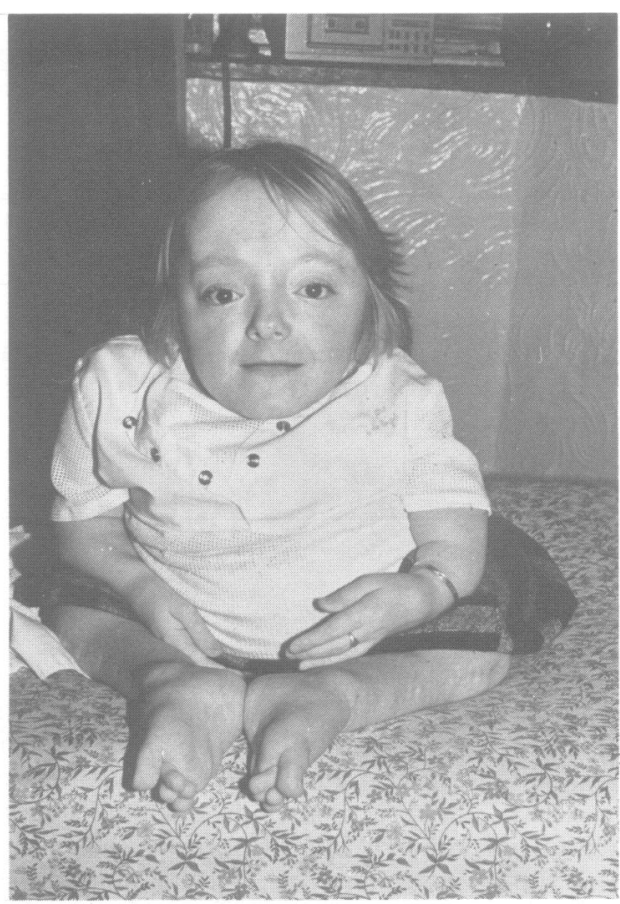

FIG 2 A 14 year old girl with severe, progressively deforming OI (type IIIIIIV). 


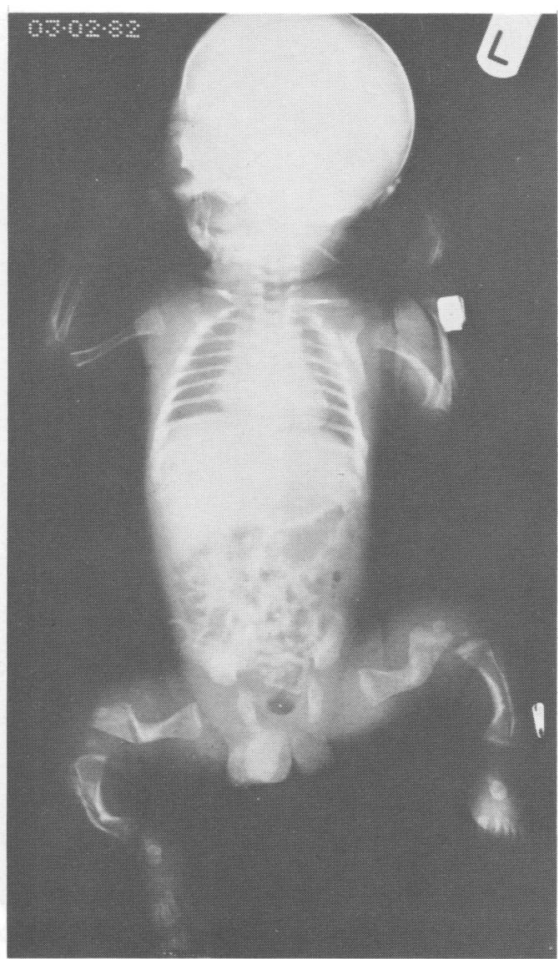

FIG 3 Radiograph taken on day I after birth at term of a child with severe, progressively deforming OI (type III/IV) who is now aged four years. Note moderate shortening of long bones. Femora show some modelling with thin angulated diaphyses and flared metaphyses. The ribs are slender, the humeri are well modelled, and the skull shows good mineralisation.
80 cases were less than -6 SD below the mean in all but eight cases. Apart from three with radiological type IIB OI [see section (c)(ii)] these patients represent a heterogeneous group and correspond in general to the overlapping group of Sillence type III and sporadic type IV. Fig 2 shows a patient in this group.

(c) Radiographical appearance in the first week of life Radiographs taken in the first week of life were available in 40 cases and comprised a complete 'babygram' in 34 and incomplete radiographs in six. These revealed one of two main patterns.

\section{(i) Type III/IV OI pattern}

Most cases (37/40) had the following pattern, shown in fig 3. The femora were shortened with flared metaphyses probably due to multiple small fractures. The diaphyses were thin and showed a moderate degree of modelling and often mid-shaft angulation. The overall appearance of the femur was like an apple core and was seen in 36/37 cases. In nine of these, the length of the femora was a little greater than in the rest, but overall the changes were more severe than in type I OI. After about one month, the femur developed an unmodelled rectangular appearance, presumably due to callus formation around the mid-shaft (fig 4).

The ribs were generally slender with or without acute fractures. In 2/32 there were multiple discontinuous 'beads' on the ribs, presumably due to fractures with callus formation. Both children are alive at 10 and 30 months respectively.

The humeri were usually well modelled.

The skull was usually well mineralised, revealing multiple wormian bones.

The vertebral bodies were usually of normal height but showed platyspondyly in 4/32 cases.

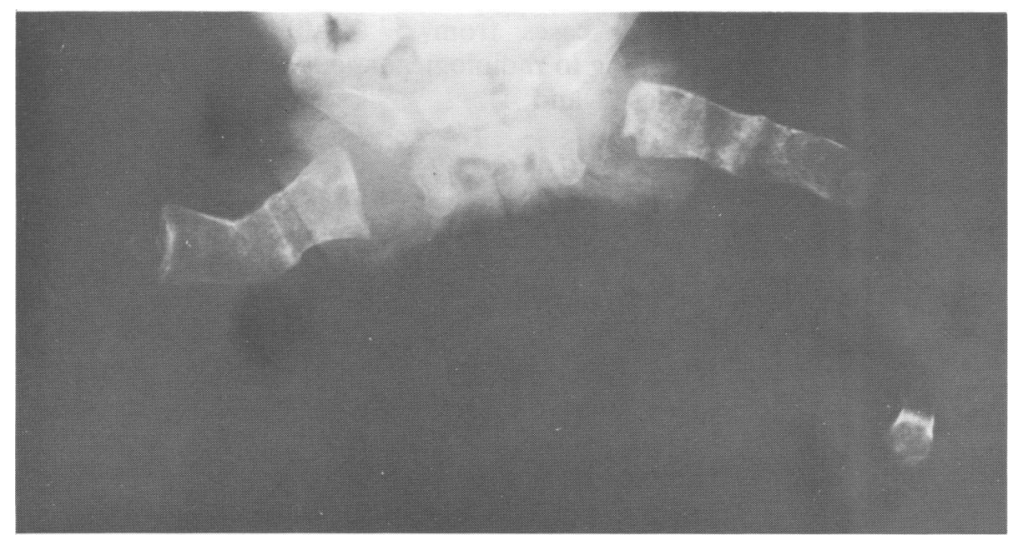

FIG 4 Radiograph of femora of a child with III/IV Ol taken at one month. Note that the femora have become thick and unmodelled, whereas on day 2 they were as in fig 3. 
The tibiae were usually angulated at the junction of the upper $2 / 3$ and lower $1 / 3$, except in one child who was a breech presentation with extended legs; his tibiae were straight.

The number of discrete fractures was often very difficult to count accurately, but ranged in number from four to 30 , with a mean of about nine. Seven of 40 of these patients died; five died under six months and the other two at 14 months and 46 months. Neonatal $x$ rays were available for only one pair of sibs (family 7, fig 5) and both showed the same radiological pattern as described above. The radiological picture described is similar to that described by Sillence for type III OI, ${ }^{17}$ but we believe these patients represent a heterogeneous type III/sporadic IV group.

\section{(ii) Type IIB OI pattern}

Three cases showed the radiographical pattern of OI type IIB with broad, rectangular, unmodelled, crumpled femora, thin ribs with multiple discontinuous beads, some modelling of humeri, platyspondyly (in one out of the three), and angulated tibiae (fig 6). These three patients died at four weeks, six weeks, and 26 months respectively. These

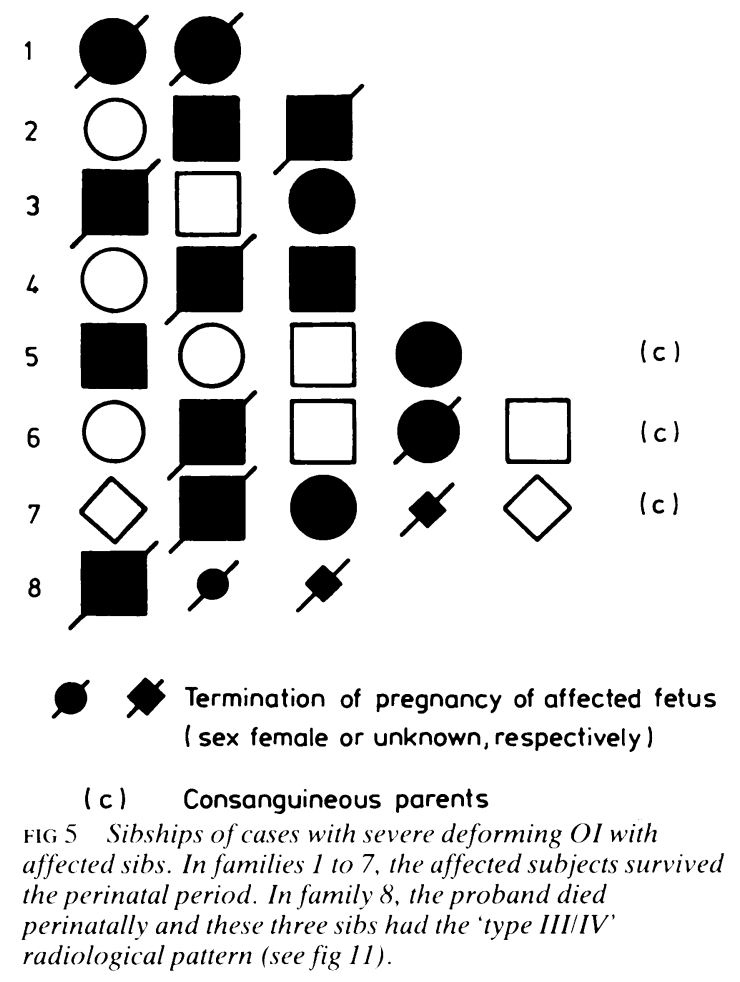

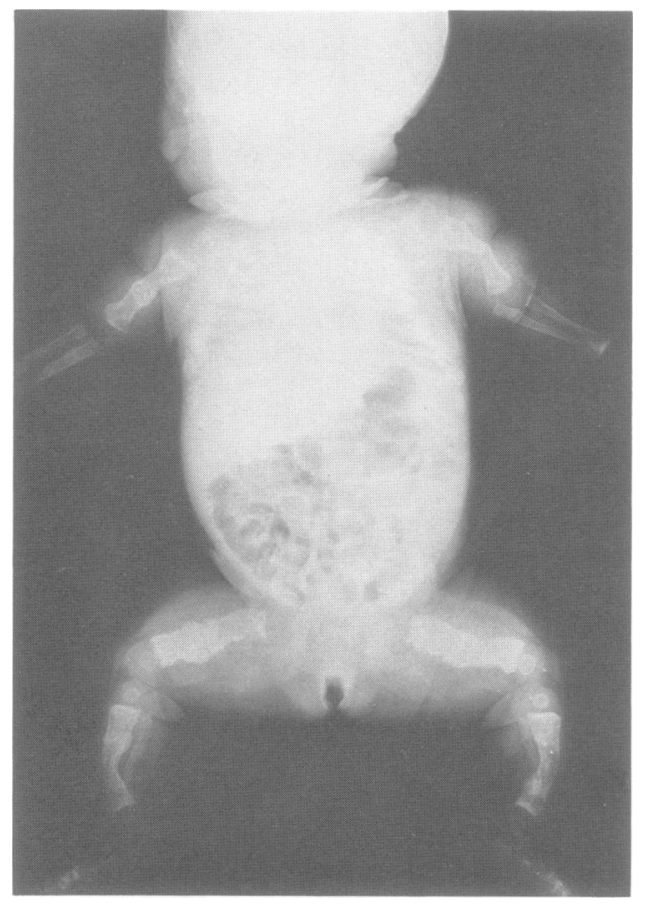

HIG 6 Radiograph taken on day 5 of a girl who died at four months. Note that the femora are short and unmodelled, the ribs are thin with occasional beads, the humeri are short with some modelling, the skull shows some mineralisation, and there is platyspondyly of some vertebral bodies. This appearance is that of IIB (see fig 7) rather than III/IV (fig 3).

results are summarised in tables 3 and 4 . It iso noteworthy that no perinatal survivor had the appearance of type IIA OI.

2. Patients with perinatally lethal ()I (stillborn or died음 within one week of birth)

The 60 cases from 57 families were classifiedo according to radiological appearance where possible (tables 3 and 4 ).

(a) Type IIA OI

Thirty cases had type IIA OI with 38 sibs, allo healthy, as described in the previous paper.

(b) Type IIB OI

Seventeen cases were initially classified as typ? IIB. ${ }^{23}$ Subsequently we recognised that only 12 of these (from 11 families) conformed to the radio- $\overrightarrow{\mathbb{D}}$ logical description for IIB of Sillence et al. ${ }^{2}$ This $\vec{D}$ consists of short, broad, crumpled, unmodelled $\frac{\varrho}{\sigma}$ femora and thin ribs with multiple discontinuous 
TABLE 3 Radiological features at birth.

\begin{tabular}{|c|c|c|c|c|c|c|}
\hline Type of $\mathrm{Ol}$ & Femora & Ribs & Humeri & $\begin{array}{l}\text { Skull } \\
\text { mineralisation }\end{array}$ & $\begin{array}{l}\text { Height of } \\
\text { vertebral } \\
\text { bodies }\end{array}$ & Tibiae \\
\hline IIA & $\begin{array}{l}\text { Very short. } \\
\text { broad. } \\
\text { unmodelled }\end{array}$ & $\begin{array}{l}\text { Broad. } \\
\text { continuous } \\
\text { beads }\end{array}$ & $\begin{array}{l}\text { Like } \\
\text { femora }\end{array}$ & Absent & Flat & Angulated \\
\hline IIB & $\begin{array}{l}\text { Very short. } \\
\text { broad. } \\
\text { unmodelled }\end{array}$ & $\begin{array}{l}\text { Thin } \pm \\
\text { discontinuous } \\
\text { beads }\end{array}$ & $\begin{array}{l}\text { Some } \\
\text { modelling }\end{array}$ & Near normal & Near normal & Angulated \\
\hline IIC $^{*}$ & $\begin{array}{l}\text { Short. poorly } \\
\text { modelled. } \\
\text { multiple } \\
\text { angulations }\end{array}$ & $\begin{array}{l}\text { Thin. } \\
\text { irregularly } \\
\text { shaped }\end{array}$ & Like femora & Poor & Near normal & Angulated \\
\hline III/IV & $\begin{array}{l}\text { Moderately } \\
\text { short. } \\
\text { diaphyses } \\
\text { thin and } \\
\text { angulated with } \\
\text { some modelling. } \\
\text { metaphyses flared. } \\
\text { Overall. femur } \\
\text { looks like an } \\
\text { apple core }\end{array}$ & $\begin{array}{l}\text { Thin. } \\
\text { rarely with } \\
\text { discontinuous } \\
\text { beads }\end{array}$ & Well modelled & Normal & Usually normal & Angulated \\
\hline
\end{tabular}

"Hallmarks: irregularity of bone shape, speckled calcification. and long. downward pointing ischia.

TABLE 4 Classification of cases of severe OI, born with fractures to unaffected parents, based on radiographical appearance within the first week of life.

\begin{tabular}{|c|c|c|c|}
\hline Cases & $\begin{array}{l}\text { No of perinatal survivors } \\
\text { (lived beyond first week) }\end{array}$ & $\begin{array}{l}\text { No of perinatal lethal cases } \\
\text { (stillborn or died in first week) }\end{array}$ & Total \\
\hline Total & 105 & $60)$ & \\
\hline \multicolumn{4}{|l|}{$\begin{array}{l}\text { Radiographical appearance } \\
\text { at birth }\end{array}$} \\
\hline Type IIA & (1) & 30 & 30 \\
\hline Type IIB (fig 7) & $3 \dot{H}$ & 12 & 15 \\
\hline Type IIC (fig 12) & 0 & 3 & 3 \\
\hline $\begin{array}{l}\text { Original } x \text { ray at birth } \\
\text { now unavailable }\end{array}$ & $65\}$ deforming OI & 10 & \\
\hline
\end{tabular}

* See previous paper by Young et al.

$\dagger$ The patients died at four weeks. six weeks. and 26 months, but had the typical IIB $x$ ray pattern at birth.

$千$ Total No of type III/IV is $37+5+65$ (sec text).

beads (11/12 cases) (fig 7) or without beads (one case, an 18 week terminated fetus). This contrasts with the thick, continuously beaded ribs in type IIA OI shown in the previous paper. In addition, we noted that these patients with IIB OI have better modelled humeri, better skull mineralisation, and more normal height of vertebral bodies than those with type IIA. All had angulated tibiae. In two single cases (delivered at 23 and 36 weeks) the thickness of the ribs was intermediate between IIB and IIA OI; since the other features were more typical of IIB, they were classified as such. Another single case (born at 34 weeks) had longer femora than the others, but these were completely unmodelled and the other features were consistent with IIB. There was one affected sib pair and the others were single cases. The affected sibs had the same radiological appearance (figs 7 and 8).

Nine of the 12 babies were liveborn, at a mean gestational age of 37.6 weeks (range 34 to 41 weeks), two were terminations at 18 and 23 weeks after detection of bone shortening and deformity at ultrasound scan, and in one these details were unavailable. The mean duration of survival of the nine liveborn babies was about 14 hours, range one to 48 hours. There were six females and six males. Fig 9 shows a baby with IIB OI.

The other five babies (from three families) who died perinatally, and who were originally classified as IIB ${ }^{23}$ in fact had radiological appearances similar to those described in (c) (i), that is, with the type III/IV appearance (fig 10). One index case was 


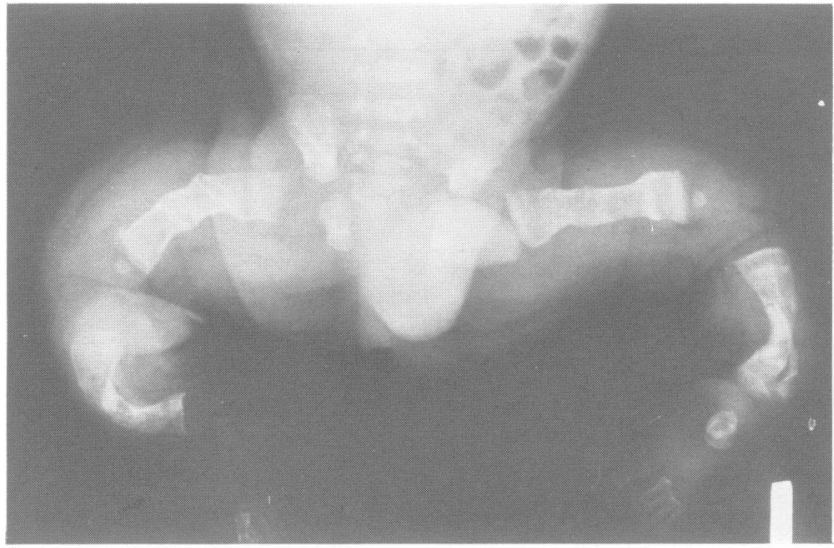

(a)

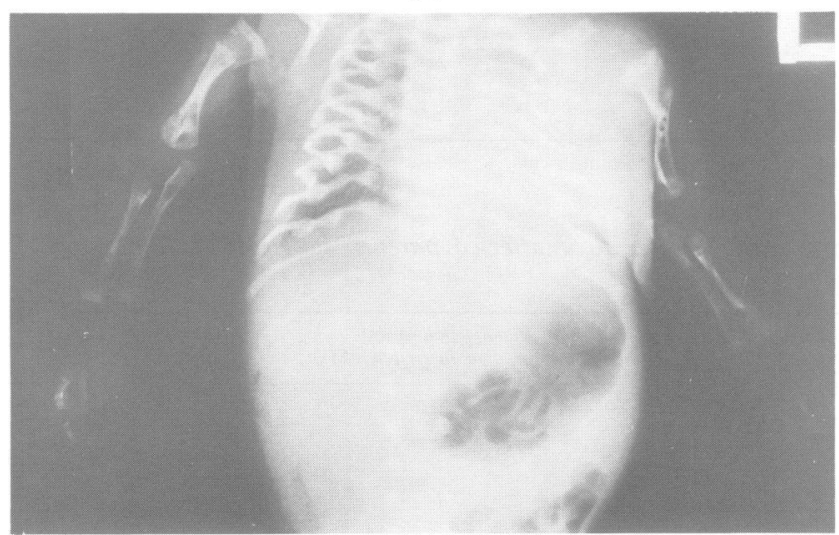

stillborn at 30 weeks and two were liveborn at 38 weeks and lived 24 and 10 hours respectively. The first two babies were single cases in their family, but the third had two affected sibs in whom the disease was detected prenatally by ultrasound scan and confirmed radiologically after termination of pregnancy. These three sibs had the same radiological appearance (fig 11 a-d).

\section{(c) Type IIC OI}

Three cases were classified as type IIC OI on the basis of broad, irregular femora, thin, irregular, discontinuously beaded ribs, irregularly shaped humeri, poor skull mineralisation, near normal height of vertebral bodies, and angulated tibiae (fig 12). The pelvis showed flared ilia and long ischia which pointed downwards. The hallmarks of this type of OI appear to be irregularity of bone shape, including of the scapulae, and speckled calcification. Two of the three cases were stillborn at 28 and 30 weeks. In the other case, the pregnancy was terminated at 19 weeks' gestation after detection of skeletal abnormalities during routine ultrasound scanning.

(d) Unclassifiable perinatally lethal $O I$ In 10 cases, the diagnosis of OI had originally bee㱜 made on $x$ ray appearance, but as the radiograpl\$ was no longer available, classification was not possible. Seven were liveborn, mean gestational age in six was 35.7 weeks (range 34 to 40 weeks), and no. baby survived longer than one hour. Three babies were stillborn at 31 and 32 weeks; gestational' ag@ was unknown in the other.

B. RECURRENCES IN SIBS

1. Survivors of the perinatal period with severe $O E$ A total of 105 cases from 98 families was studie क् (tables 2 and 4). There were seven families with recurrences (fig 5). Since each family was ascerō tained only once, one child (usually the older) waథ taken as the proband and affected sibs were counte $\Phi^{\circ}$ only once. In this group overall, there were 142 sibs eight of whom were affected (including the fetus if 


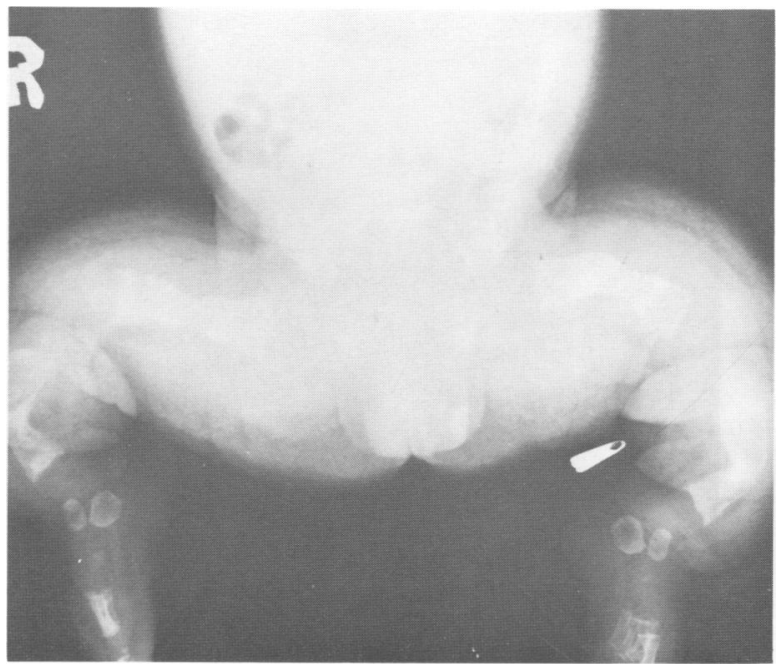

(a)

FIG 8 Radiographs of the legs (a) and chest (b) of the female sib of the patient shown in fig 7. She was born at 39 weeks, died at 48 hours, and has the same radiographical appearance as her brother.

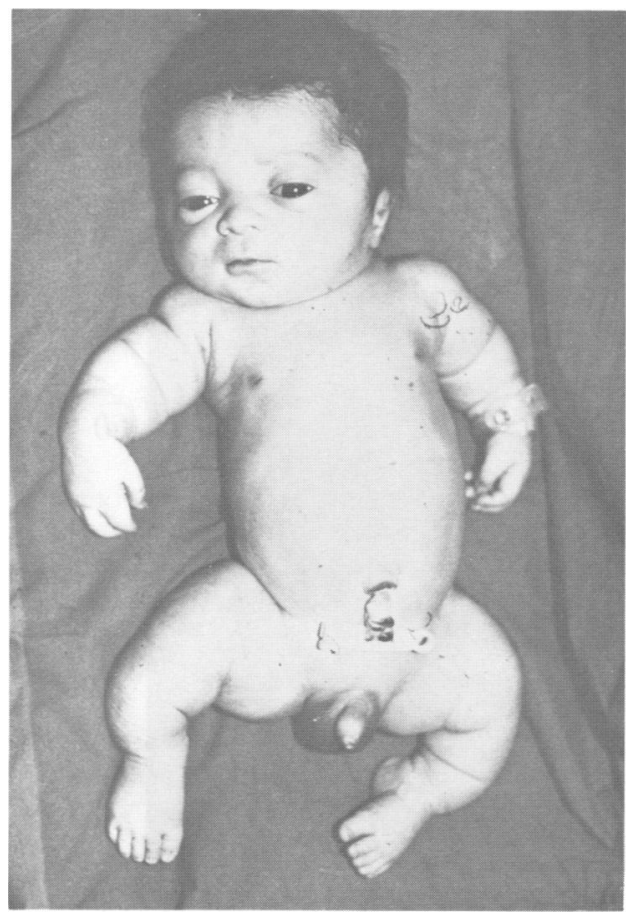

FIC 9 A baby with the type IIB radiographical appearance who died at 24 hours. He was delivered at 41 weeks.

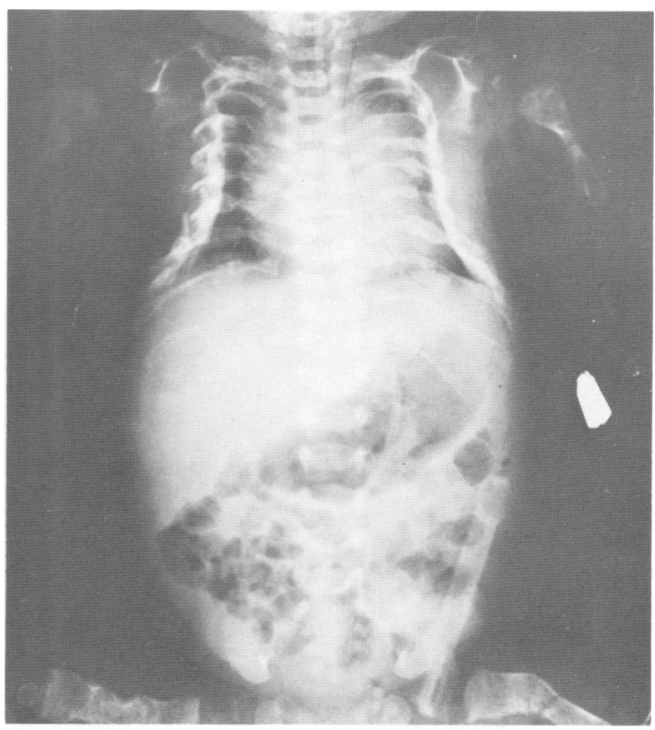

(b)

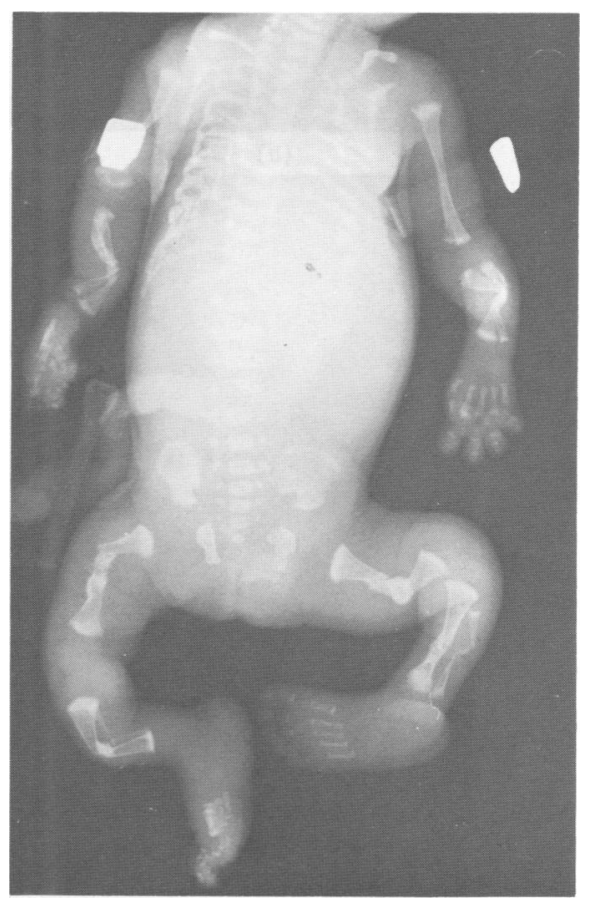

FIG 10. Radiograph of a stillborn female delivered at 30 weeks' gestation. Note that the length and modelling of the long bones are much better than in IIB. (This is not necessarily attributable to gestational age, since the IIB appearance can be recognised in fetuses-see discussion.) The ribs are thin and discontinuously beaded. The appearance is more like that of III/IV OI (fig 3) than IIB (figs 7 and 8 ). 

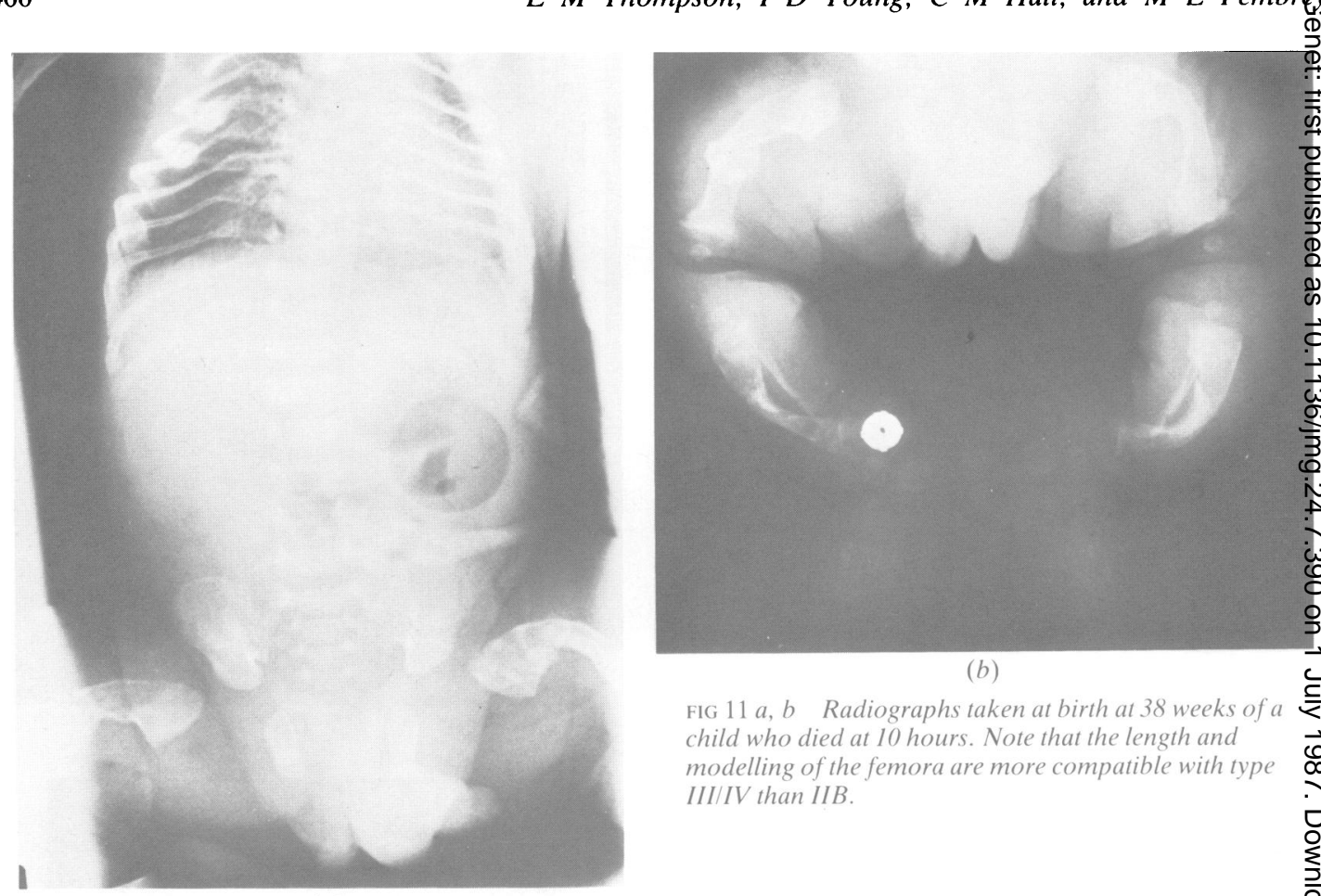

(b)

$\stackrel{\varrho}{\grave{c}}$

FIG 11 a, $b$ Radiographs taken at birth at 38 weeks of $a$ child who died at 10 hours. Note that the length and modelling of the femora are more compatible with type III/IV than IIB.

(a)
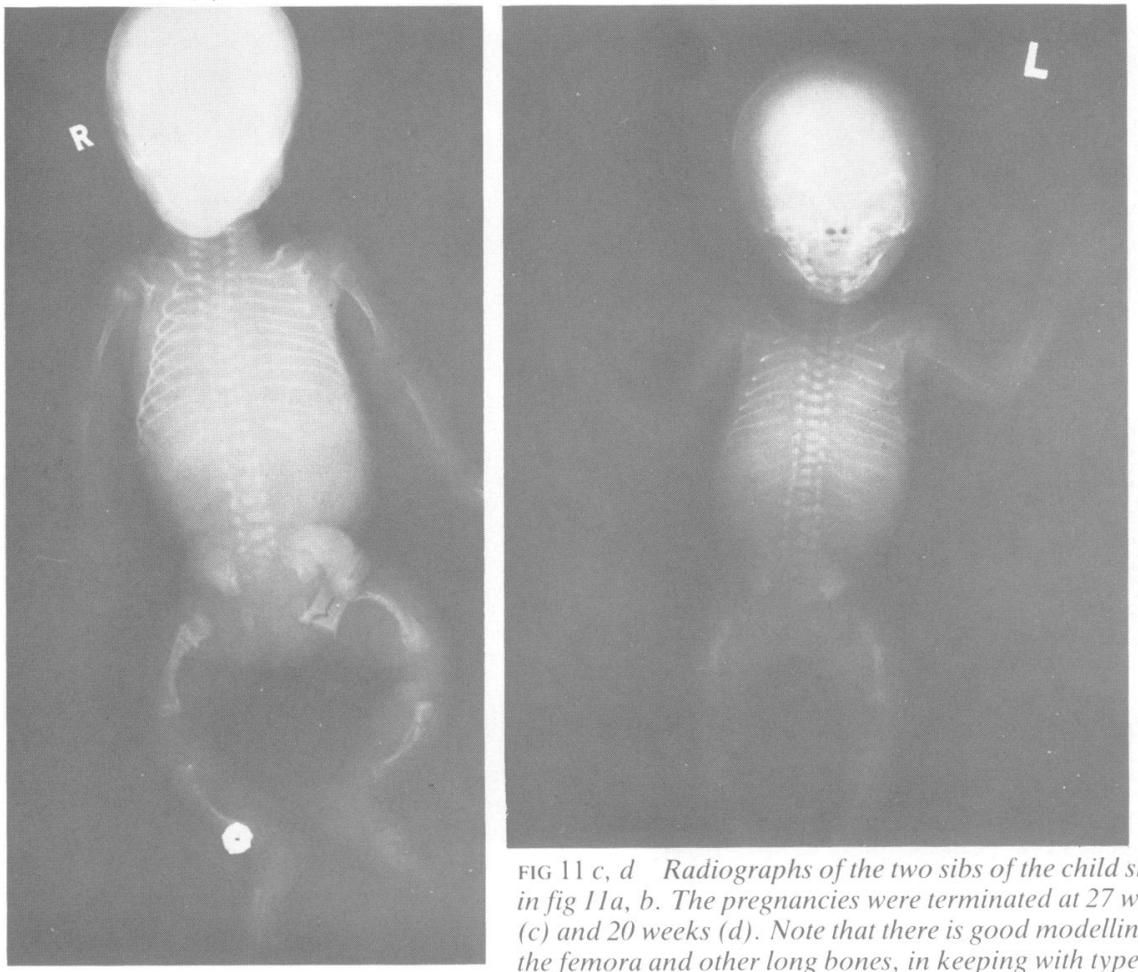

FIG $11 c, d$ Radiographs of the two sibs of the child shown in fig II $a, b$. The pregnancies were terminated at 27 weeks (c) and 20 weeks (d). Note that there is good modelling of $O I$. 


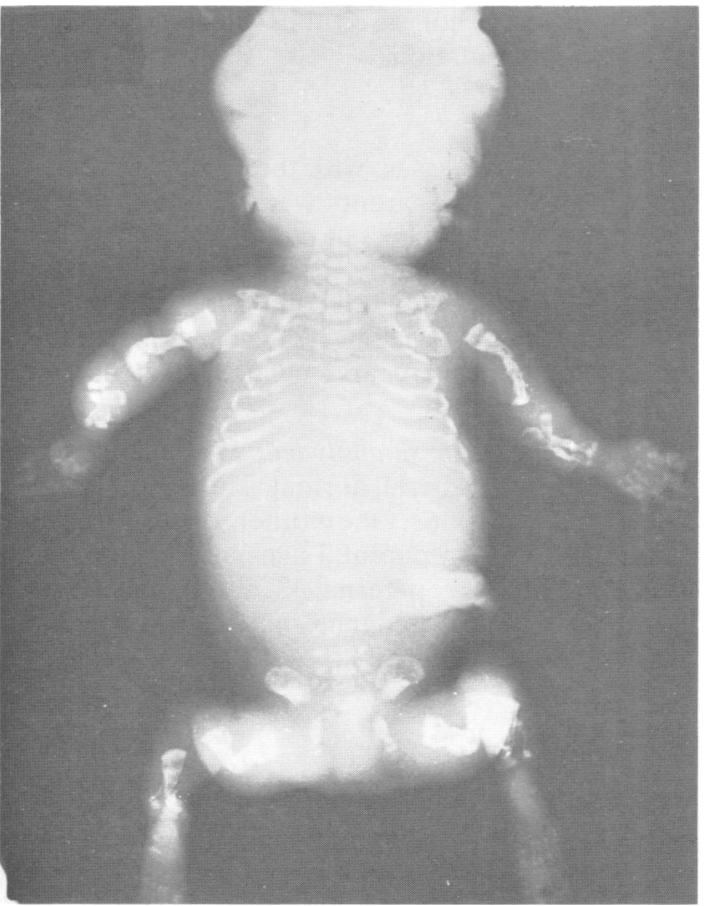

FIG 12 Radiograph of a baby stillborn at 28 weeks with IIC $O I$. Note the shortening of long bones, especially the femora which show multiple angulations, the thin, irregular ribs, the absence of skull mineralisation, the fairly normal vertebral body height, and the long, downward pointing ischia. The bone shape is generally irregular with speckled calcification.

family 7 , fig 5), giving an empirical recurrence risk of $5 \cdot 6 \%$.

However, in this analysis, it is more logical to exclude the three (single) perinatal survivors with radiological type IIB OI [see section $\mathrm{A} 1$ (c)(ii)], and to include the five cases (from three families) with perinatally lethal disease but with the type III/IV radiological appearance [see section A2(b) and table 4], since consistency in radiological appearance is more likely to indicate a true subgroup than is age of death. The latter five cases included a sibship of three affected babies ascertained only once. This group therefore consisted of 107 cases (plus the fetus in family 7). Again taking one child per family as the proband, there were 98 probands who had 146 sibs of whom 10 were affected, giving an empirical recurrence risk of $6 \cdot 9 \%$. It could be argued that since neonatal $x$ rays were available in only 40 cases, it is invalid to include in the analysis those with no neonatal $x$ rays. However, the maximum age at death of a child with IIB OI was 26 months, and of the perinatal survivors with no neonatal $x$ rays, only nine had died under 26 months. Extrapolating from the fact that three of 40 with neonatal $x$ rays were found to be IIB, then about one other $(3 / 40 \times 9=0.675)$ could in fact be expected to have IIB OI.

Sixty of the 146 sibs $(41 \%)$ were post-born. Of the mothers of single cases, 16 gave a history of one early spontaneous miscarriage, two of two, and one of five miscarriages. Of the mothers of affected sibs, two reported one miscarriage each and one mother reported two.

The eight families with affected sibs are shown in fig 5. In families 5, 6, and 7 the parents are first cousins; all come from ethnic groups in which consanguinity is common. The parents in family 5 were Jordanian, in family 6 they were Pakistani, and in family 7 they were Welsh gypsies. The parents of the mother in the latter family were also consanguineous and she was said to have had affected sibs. In the other five families the parents were unrelated and British, except for the father in family 3 who is German. Consanguinity was present in one other family in which the parents of a single case were first cousin Pakistanis (fig 13). The mother's two sibs (III.6, III.7) were born in Pakistan and were said to have 'brittle bones'. They died at one week and one year respectively. One of the single cases who died at four months was said to have a great aunt with OI and another single case was said to have a cousin who had had several fractures. In both, the two intervening relatives were normal.

There were no clinical or radiological features which distinguished cases with affected sibs from sporadic cases.

\section{Parental ages}

Mean parental ages at the birth of the sporadic cases (excluding the presumed recessive single case shown in fig 13) were raised above that of a control popu-

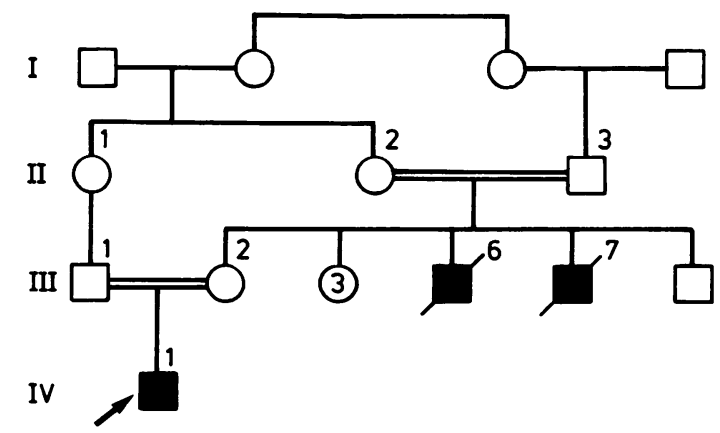

FIG 13 Pedigree of a proband (IV.1) with severe deforming $O I$ whose parents were first cousins. III.6 and III. 7 were reported to have OI. It is assumed that the disease is recessively inherited in this family and that II.I, II.2, II.3, III.1, and III. 2 were heterozygotes. 
lation, but this was not statistically significant (table 5 ). The control means were calculated from data obtained from the Office of Population Censuses and Statistics Series FMI (HV). ${ }^{24}$ Since the study group were born between 1930 and 1985, an average of the population means (when available) was calculated, and it was weighted according to the number of study cases born in each year. Figures for "legitimate births for all birth orders" were used, since 88 out of 89 cases were legitimate births.

\section{Type II OI}

\section{(a) Type IIA}

There were no recurrences in 38 sibs (see previous paper).

\section{(b) Type IIB}

There were 12 cases from 11 families ascertained through the perinatally lethal survey, and three cases from three families ascertained through the BBS who died beyond the perinatal period [see A1 (c)]. These 15 cases had 13 sibs, one of whom was affected, giving an empirical recurrence risk of $7 \cdot 7 \%$. Nine sibs were post-born and four pre-born. Parents were consanguineous in three families; in family 1 they were first cousin Pakistanis, in family 11 , a West Indian family, the child was born of an incestuous union, and in family 12 the parents were first cousin Sri Lankan Christians. The latter two families come from racial groups in which consanguinity is uncommon. Parents in the other 11 families were unrelated; 10 couples were Caucasian and one was Negro. None of the mothers reported having any early spontaneous miscarriages. Mean parental ages at the birth of the (first) affected child were: paternal 25.44 years $(n=$ 11 , range 15.9 to 34.58 years); maternal 22.28 years $(n=14$, range $13 \cdot 25$ to $27 \cdot 5$ years). If the three families with consanguineous parents are excluded, the mean parental age at the birth of the affected child are paternal 24.36 years $(n=9$, range 15.9 to 32.92 years) and maternal $22 \cdot 51$ years $(n=11$, range $16 \cdot 4$ to $27 \cdot 2$ years), which are not raised above the parental ages the general population.

\section{(c) Type IIC}

There were three cases, with three sibs, all of whon were healthy. The parents were all unrelated; tw pairs were Caucasians and one was Negro. Th民 mothers reported no early miscarriages. Parental age at the birth of the affected child were paternal $20.9 \%$ $28 \cdot 5$, and $25 \cdot 8$ years (mean 27.77 years) and maternat $27 \cdot 67,27 \cdot 0$, and $25 \cdot 2$ years (mean $26 \cdot 62$ years).

\section{(d) Unclassifiable perinatally lethal OI}

Ten cases had 22 sibs, all normal. The parents were ali unrelated Caucasians. One mother reported one earlyw miscarriage. Mean parental ages at the birth of the्g affected child were: paternal 32.72 years $(n=9$, range 22.33 to 49.7 years) and maternal 27.98 years $\left(n=10^{\circ}\right.$ range 18.5 to 39.75 years).

\section{Discussion}

We studied a large group of patients with severe deforming OI, born with fractures to normal parents. in order to determine recurrence risks. Patients whe died in the perinatal period were ascertained differo ently from those who survived it. The majority of the latter (for whom $x$ rays were available) had $\$$ characteristic radiographical appearance in the first week of life, which corresponds to that described $b \pm$ Sillence et $a l^{17}$ for type III OI. These patients represent a heterogeneous group of 'type III' an\$ 'sporadic type IV'. The patients who died within one week of life mostly had type IIA OI, some had types IIB, a minority IIC, and some were not classifiableo In addition, five patients with perinatally letha disease from three families had the 'type IIB radiographical appearance. This draws attention to some important points regarding classification and prognosis.

TABLE 5 Mean parental ages at the birth of the sporadic type III/IV cases.

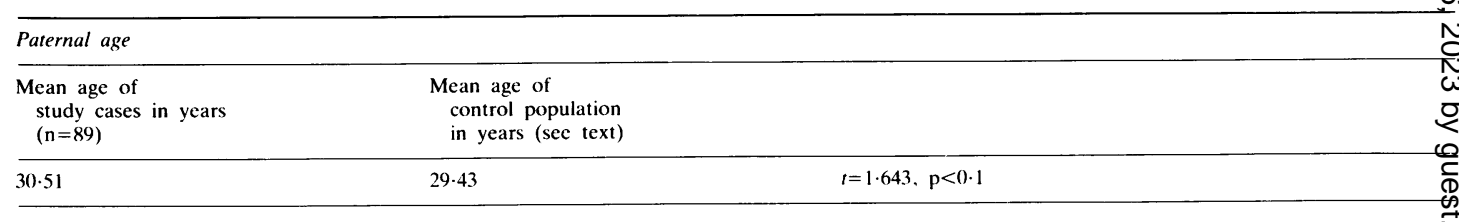

Maternal age

Mean age of

study cases in years control population

$(\mathrm{n}=89)$

in years (see text)

$27 \cdot 82$

$27 \cdot 16$

$t=1 \cdot 313, \mathrm{p}<0 \cdot 1$ 
CLASSIFICATION

The use of the term 'perinatally lethal' to describe type II OI is a potential source of confusion, implying that time of death determines type. It is probably more useful to separate patients into radiological groups at birth where possible and this was recently emphasised by Sillence et al. ${ }^{7}$ It must be stressed that the $x$ ray taken during the first week of life determines type IIB or III/IV. Even at one month callus formation can make a well modelled femur look thick (fig 4). These bones later become progressively thinner. Suggestions that type IIB and III OI overlap may relate to emphasis on time of death and failure to compare the first week $x$ rays of sibs. For example, Spranger et $a l^{25}$ suggested that the two sibs described by Glanzmann ${ }^{8}$ show type III (the girl) and type IIB (the boy). The girl was alive at nine years and her first week $x$ rays were not presented; her brother died at five months. His radiograph revealed thick long bones, but was taken at four weeks of age, so that it is not possible to classify him as IIB or III. Although it is possible that the type IIB appearance at birth is only a more severe form of type III, support for the separate identities of the radiological appearance at birth of the two types is the fact that it was shown to 'breed true' in three sets of sibs (one set of IIB and two sets of 'III' OI) in our study. It has to be said that some cases are difficult to classify even on radiological appearance, so that two (single) cases had intermediate rib thickness making differentiation between IIA and IIB difficult, and one baby with very poor modelling (like IIB) had surprisingly good femoral length, as in the type III appearance [see section A2 (b)].

\section{PREDICTION OF PROGNOSIS BY}

RADIOGRAPHICAL APPEARANCE AT BIRTH

The radiological appearance at birth can be used to predict prognosis to a certain extent. Prognosis is worst in type IIC OI in which six of seven cases (this report and Sillence et $a l^{2}$ ) were stillborn; the other was a second trimester termination. Prognosis is also very bad in type IIA: none of our patients who lived beyond one week of life had the type IIA OI appearance, although Sillence et $a l^{2}$ reported maximum survival to six weeks in type IIA OI. Patients with the radiographical appearance of type IIB also have a poor prognosis in terms of survival, but survival may be a little longer than in IIA. Of our 15 cases, 12 were liveborn and nine died before 48 hours. The other three died at four and six weeks and 26 months. Maximum survival reported by Sillence $e t a l^{2}$ was to six weeks. Goldfarb and Ford ${ }^{26}$ reported two sibs with probable IIB OI who died at five months and five and a half months and Hein ${ }^{27}$ described a daughter of first cousin parents with probable IIB OI who died at five months. Chawla ${ }^{28}$ reported four sibs with severe congenital OI. The $x$ ray of one taken on day 3 was consistent with IIB OI. He died at nine months and his affected sibs died at three years, 24 hours, and four months of age. Patients with the type III/IV appearance at birth may be stillborn (one case) or liveborn, but die within 24 hours (two cases). The vast majority (103 cases) survived the perinatal period but one quarter died in childhood, more than half of these before two years, and the majority of deaths had occurred by 10 years. Sporadic cases with only mild bowing at birth will usually have mild disease (fig 1) and probably represent new dominant mutations.

Essentially, the better the bone morphology at birth, the longer the survival. This is similar to the results of the scoring system devised by Spranger et al. ${ }^{29}$ Similarly, Shapiro, ${ }^{30}$ in a review of 85 patients with OI, found that poor bone morphology at birth or at the time of initial fracture predicted a worse prognosis for survival and ambulation.

\section{RECURRENCE RISKS (TABLE 6) \\ Type III/IV group}

The empirical recurrence risk of $6.9 \%$ is likely to be a maximum, because if any bias in ascertainment were present it would be towards finding affected sib pairs whose families are more likely to join the BBS or to be known to clinical geneticists. The recurrence risk could have been underestimated if parents had been deterred from further reproduction after the birth of one affected child. This does not appear to have been the case, since, of the 146 sibs, $41 \%$ were born after the proband.

The recurrence risk of $6.9 \%$ in this study is consistent with the disease arising as a new autosomal dominant mutation in $72.4 \%$ of these families and as an autosomal recessive in only $27.6 \%$, assuming that these are the two genetic mechanisms operating. It would be expected that the autosomal recessive cases would be overrepresented in families in which the parents are consanguineous and this appears to be the case. If the four families with consanguineous parents are excluded (figs 5 and 13) then the empirical recurrence risk in families with unrelated parents is $4.4 \%$ (six affected sibs out of 135 sibs of 104 cases).

The current study has specifically addressed the problem of recurrence risk in sporadic cases of $\mathrm{OI}$ born with fractures. We recognise that there are 'late onset' autosomal recessive forms, as reported by Sillence et al, ${ }^{7}$ Lièvre, ${ }^{11}$ Awwaad and Reda (family 2), ${ }^{12}$ and Horan and Beighton, ${ }^{13}$ but these are probably rare. 
TABLE 6 Recurrences.

\begin{tabular}{|c|c|c|c|c|c|}
\hline Type of $\mathrm{OI}$ & Cases & Total sibs & Affected sibs & $\begin{array}{l}\text { Recurrence } \\
\text { risk }(\%)\end{array}$ & Comment \\
\hline IIA & 30 & 38 & 0 & 0 & $\begin{array}{l}\text { Rare reports of affected } \\
\text { sibs suggests a small } \\
\text { recurrence risk } \\
\text { should be quoted (sec } \\
\text { previous paper) }\end{array}$ \\
\hline IIC & 15 & 13 & 1 & $7 \cdot 7$ & $\begin{array}{l}\text { Overall evidence suggests } \\
\text { higher recurrence risk } \\
\text { in these rare forms } \\
\text { (see text) }\end{array}$ \\
\hline \multirow{2}{*}{$\begin{array}{l}\text { III/IV } \text { All cases } \\
\text { Parents non- } \\
\text { consanguineous }\end{array}$} & 107 & 146 & 10 & 6.9 & - \\
\hline & 104 & 135 & 6 & 4.4 & - \\
\hline All perinatally lethal cases & 60 & 80 & 3 & $3 \cdot 8$ & $\begin{array}{l}\text { This provides a recurrence } \\
\text { risk figure if a } \\
\text { perinatally lethal case } \\
\text { is unclassifiable }\end{array}$ \\
\hline
\end{tabular}

Recurrence risk in IIB OI

The recurrence risk of $7.7 \%$ (one in 13) is similar to that in the type III/IV cases, but the numbers are considerably smaller. In addition, consanguinity was present in three families. Two of these come from racial groups where consanguinity is uncommon. Other examples of probable type IIB OI in sibs have been reported. ${ }^{26} 283132$ The parents of the single case of probable type IIB OI described by $\mathrm{Hein}^{27}$ were consanguineous, as were those in the pedigree of Zeitoun et al. ${ }^{31}$ Several fetuses with probable type IIB OI were detected as early as 16 weeks of pregnancy by ultrasonography. ${ }^{33-36}$ After termination of pregnancy, the $x$ rays of the fetuses were consistent with IIB OI. Even in the second trimester, the femora were short and broad and the ribs were thin. Each case had one or more affected sibs, whose $x$ ray was presented in only one instance ${ }^{33}$ and was consistent with IIB OI. An additional feature in one affected baby was polydactyly and his affected sib had amniotic bands leading to finger amputations. ${ }^{35}$ One of the two affected sibs of the fetus described by Patel et $a l^{34}$ had cleft lip and palate and anencephaly. The parents in the family of Ghosh et al $^{36}$ were consanguineous. Overall, the evidence is probably in favour of autosomal recessive inheritance in this group. Prenatal diagnosis of pregnancies at risk of type IIB (and IIC) OI can be offered using careful serial ultrasonography in the second trimester. Occasionally, cases will be detected on routine scans, as happened in two of our patients.

\section{Recurrence risk in IIC OI}

The numbers in our study are too few to draw conclusions regarding mode of inheritance. Sillence et $a l^{2}$ described four cases in two families, three of whom were from one sibship, suggesting autosomat recessive inheritance.

\section{Unclassifiable perinatally lethal $\mathrm{OI}$}

If genetic counselling were requested after the birth of a child with radiologically proven perinatalle lethal OI, but the $x$ ray was lost so that classificatio was not possible, empirical recurrence risk figure of $3.8 \%$ could be given (table 6 ), derived from the number of affected sibs $(n=3)$ out of total sib@ $(n=80)$ of all cases of perinatally lethal OI $(n=60) \overrightarrow{\vec{Q}}$ Again, prenatal diagnosis by ultrasound scanning could be offered for future pregnancies.

\section{Conclusion}

We suggest that the radiological appearance at birt in severe 'sporadic' OI predicts both survival and recurrence risks to sibs.

The most severe abnormalities of bone miner alisation and morphology are seen in types IIA ang IIC, and these babies rarely survive the perinatab period. In type IIA the recurrence risks are ver: low. In type IIC, the rarest form of OI, the evidenas is in favour of autosomal recessive inheritance. In type IIB the bone abnormalities are severe but les so than in IIA and IIC. The babies usually die in th perinatal period but occasionally survive for severg months. On the available information there is nof enough evidence to quote a recurrence risk of leફ5 than $25 \%$.

Sporadic cases with the moderate bone changes of 'type III' OI at birth cannot reliably be diagnosed $\$$ type III or IV. They usually survive the perinat period but about one quarter die in childhood. Th overall empirical recurrence risk is $7 \%$. In practicer we would give a risk of up to $25 \%$ if the parents are 
consanguineous and a risk of $4.4 \%$ in single cases with unrelated parents.

The authors thank the patients and their families for their enthusiastic cooperation, and Dr Colin Paterson, Mrs Margaret Grant, Miss Yvonne Grant, and Ms Alison Wisbeach of the Brittle Bone Society for their generous help. We are indebted to many colleagues for their assistance, especially Drs J Burn, J M Connor, B C C Davison, N R Dennis, D Donnai, M M Honeyman, R H Lindenbaum, G McEnery, M Oo, F M Pope, C M D Ross, D C Siggers, M Super, I W Turnbull, M Vowles, R G Welch, E M Williams, R M Winter, R WynneDavies, and Professors P S Harper and D F Roberts. Permission to publish radiographs or photographs was kindly provided by Dr L Jones (fig 4), Dr F M Pope (fig 6), Dr M M Honeyman (figs 7 and 8), Drs A H Chalmers and D C Siggers (fig 11), and Dr D Donnai (figs 9 and 12). We thank Mrs Melanie Barham for secretarial assistance and Miss Elizabeth Lord for typing the manuscript. The study was funded by a Wellcome Trust Training Fellowship held by EMT.

\section{References}

1 Sillence DO, Senn A, Danks DM. Genetic heterogencity in osteogenesis imperfecta. J Med Genet 1979:16:101-16.

2 Sillence DO, Barlow KK, Garber AP, Hall JG, Rimoin DL. Osteogenesis imperfecta type II. Delineation of the phenotype with reference to genetic heterogeneity. Am J Med Genet 1984:17:407-23.

3 Smith R. Disorders of the skeleton. Osteogenesis imperfecta. The Brittle Bone syndrome. In: Weatherall DJ, Ledingham JGG. Warrell DA. eds. Oxford textbook of medicine. Oxford: Oxford University Press, 1983: section 17.25.

+ McKusick VA. Mendelian inheritance in man. 7th ed. Baltimore: Johns Hopkins University Press, 1986: No 25942.

5 Sillence DO. Rimoin DL. Danks DM. Clinical variability in osteogenesis imperfecta: variable expressivity or genetic heterogeneity. Birth Defects 1979:XV(5B):113-29.

- Sillence D. Osteogenesis imperfecta: an expanding panorama of variants. Clin Orthop 1981;159:11-25.

7 Sillence DO. Barlow KK, Cole WG. Dietrich S, Garber AP, Rimoin DL. Osteogenesis imperfecta type III. Delincation of the phenotype with reference to genetic heterogeneity. Am J Med Genet 1986:23:821-32.

* Glanzmann E. Familiäre osteogenesis imperfecta (typus Vrolik) und ihre Bchandlung mit Vitamin D-Stoss. Bull Schweiz Akad Med Wiss 1944:1:18(1-90).

"Kaplan M. Baldino C. Dysplasie périostale paraissant familiale et transmise suivant le mode Mendelian recessif. Arch Fr Pediatr 1953:10:943-50.

1" Adatia MD. Osteogenesis imperfecta-a case report. I Indian Med Profession 1957:4:1810-2.

"Lièvre JA. La fragilite osseuse constitutionelle. Etude de 25 families comportant 53 malades. Rev Rhum Mal Osteoartic 1959:26:42(1-32 (obs 23).

12 Awwaad S, Reda M. Osteogenesis imperfecta. Review of literature with a report on three cases. Arch Pediatr 1960):77: $28(1-90)$

1. Horan F, Beighton P. Autosomal recessive inheritance of osteogenesis imperfecta. Clin Genet 1975:8:107-11.
It Aylsworth AS, Seeds JW, Guilford WB, Burns CB, Washburn DB. Prenatal diagnosis of a severe deforming type of osteogenesis imperfecta. Am J Med Genet 1984:19:707-14.

15 Rohweder HJ. Ein Beitrag zur Frage des Erbganges der Osteogenesis imperfecta Vrolik. Arch Kinderheilkd 1953;147: 256-62.

16 Maloney FP. Osteogenesis imperfecta of early onset in three members of an inbred group: ?recessive inheritance. In: Bergsma D, ed. Skeletal dysplasias: clinical delineation of birth defects. Vol IV. New York: The National Foundation-March of Dimes, 1969:219-24.

17 Nicholls AC, Osse G, Schloon HG. et al. The clinical features of homozygous $\alpha 2$ (I) collagen deficient osteogenesis imperfecta. J Med Genet 1984:21:257-62.

is Young ID. Harper PS. Recurrence risk in osteogenesis imperfecta congenita. Lancet 1980;i:432.

19 Wynne-Davies R, Gormley J. Clinical and genetic patterns in osteogenesis imperfecta. Clin Orthop 1981;159:26-35.

21 Cohen T, Goldstein N, Falevski de Leon G. Osteogenesis imperfecta in Jerusalem. Am J Hum Genet 1984:36:47S.

2 Smith R, Francis MJO, Bauze RJ. Osteogenesis imperfecta. A clinical and biochemical study of a generalised connective tissue disorder. $Q J$ Med 1975;176:555-73.

22 Beighton P. Spranger J, Versveld G. Skeletal complications in osteogenesis imperfecta. A review of 153 South African paticnts. SA Mediese Tydskrif Deel 1983:64:565-8.

23 Thompson EM, Young ID. Hall CM, Pembrey ME. Recurrence risks and prognosis in severe sporadic osteogenesis imperfecta with fractures at birth. J Med Genet 1986;23:468A

${ }^{24}$ Office of Population Censuses and Surveys. Series FMI (HV), 1986.

25. Spranger J. Osteogenesis imperfecta: a pasture for splitters and lumpers. Am J Med Genet 1984:17:425-8.

${ }^{26}$ Goldfarb AA, Ford D. Osteogenesis imperfecta congenita in consecutive siblings. J Pediatr 1954:44:264-8.

27 Hein BJ. Osteogenesis imperfecta with multiple fractures at birth: an investigation with special reference to heredity and bluc sclera. J Bone Joint Surg (Am) 1928:10:243-7.

${ }^{2 \times}$ Chawla $S$. Intrauterine osteogenesis imperfecta in four siblings. Br Med J 1964:1:99-101.

${ }^{29}$ Spranger J, Cremin B. Beighton P. Osteogenesis imperfecta congenita. Features and prognosis of a heterogeneous condition. Pediatr Radiol 1982:12:21-7.

3) Shapiro F. Consequences of an osteogenesis imperfecta diagnosis for survival and ambulation. J Pediatr Orthop 1985:5: 456-62.

31 Zeitoun MM, Ibrahim AH, Kassem AS. Osteogenesis imperfecta congenita in dizygotic twins. Arch Dis Child 1963:38: 289-91.

32 Braga S. Passarge E. Congenital ostcogenesis imperfecta in threc sibs. Hum Genet 1981:58:441-3.

${ }^{33}$ Stephens JD. Filly RA. Callen PW. Golbus MS. Prenatal diagnosis of osteogenesis imperfecta type II by real-time ultrasound. Hum Genet 1983;64:191-3.

${ }^{34}$ Patel ZM. Shah HL. Madon PF, Ambani LM. Prenatal diagnosis of Iethal osteogenesis imperfecta (OI) by ultrasonography. Prenatal Diagnosis 1983:3:261-3.

${ }^{35}$ Elcjalde BR. Elcjalde MM. Prenatal diagnosis of perinatally Iethal osteogenesis imperfecta. Am J Med Genet 1983;14:353-9.

36) Ghosh A. Woo JSK. Wan CW. Wong VCM. Simple ultrasonic diagnosis of osteogenesis imperfecta type II in early second trimester. Prenatal Diagnosis 1984:4:235-40.

Correspondence and requests for reprints to Dr E M Thompson, Mothercare Unit of Paediatric Genetics, Institute of Child Health, 30 Guilford Street, London WCIN $1 \mathrm{EH}$. 